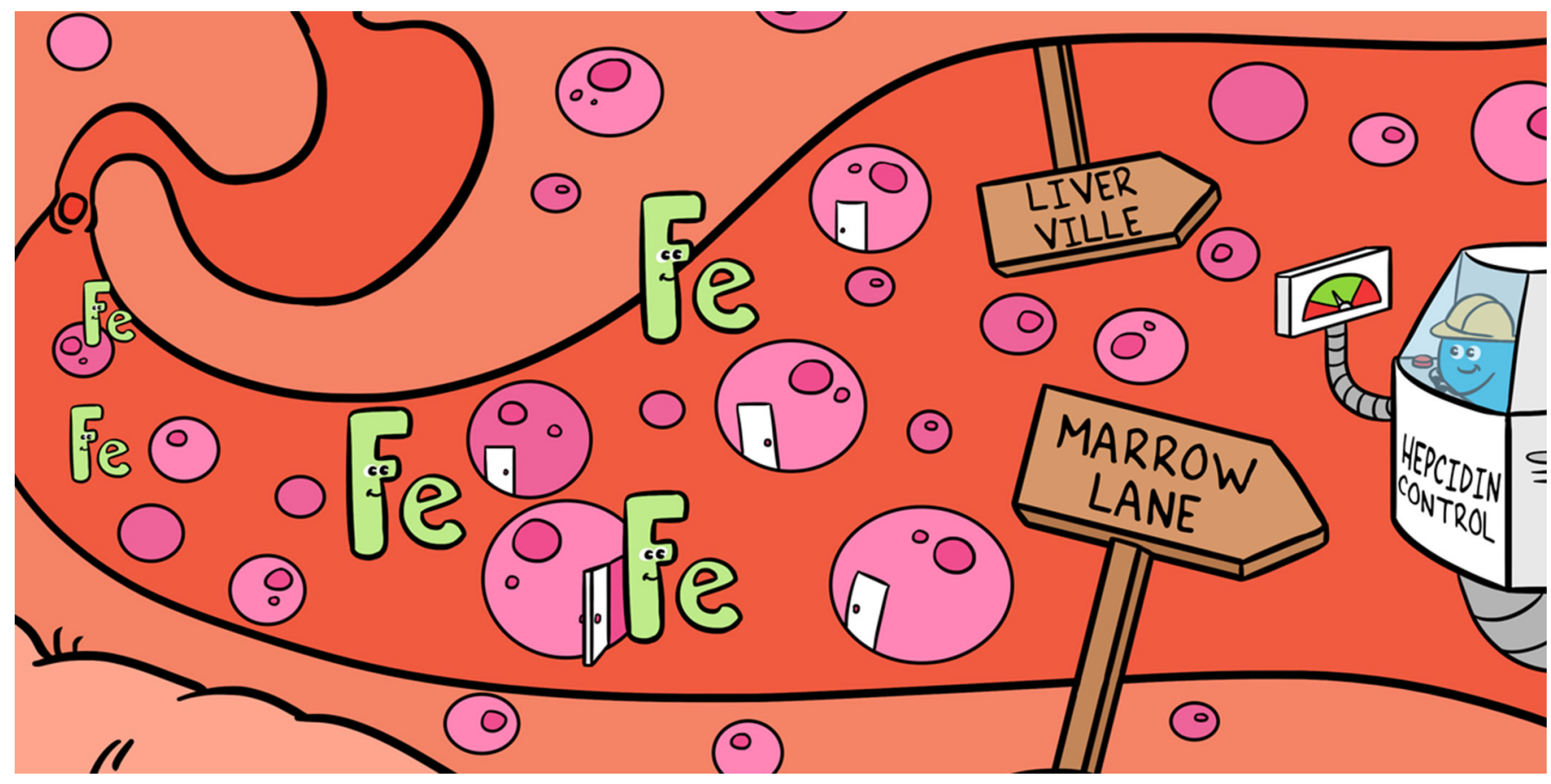

\title{
BATS, BLOOD, AND THE BIOLOGY OF IRON: IT IS ALL ABOUT BALANCE
}

\section{Leah J. Kim and Jeeyon Jeong *}

Department of Biology, Amherst College, Amherst, MA, United States

YOUNG REVIEWER:

TIANA

AGE: 13
No matter whether you are a human being, bat, or garden shrub, you need iron to survive. Iron is required for life's most fundamental processes. However, it is very toxic to the body in excess. As a result, when you have too little or too much iron in your body, it can make you very sick. In this article, we will discuss how we get enough iron and where the iron goes in our bodies after consumption. You will also find out about the diseases related to iron, including one that sickened bats at a zoo in the 1980s.

\section{SICK BATS AT THE ZOO: A STORY OF IRON}

About 30 years ago, a species of bat called the Egyptian fruit bat (Rousettus egyptiacus) started getting seriously ill at the Toronto Zoo [1]. These fruit bats got so sick that some even ended up dying. Around the same time, fruit bats at other zoos were also showing similar symptoms. What could have caused the fruit bats to get so sick? As scientists worked to find a reason, they began to rule out certain causes. For example, they did not think the illness was due to an 
Figure 1

Diet of Egyptian fruit bats in the wild and at the zoo. (A) Egyptian fruit bats normally eat a diet of (B) soft fruits, but at the zoo, (C) a powder containing iron and other nutrients was added to their food.

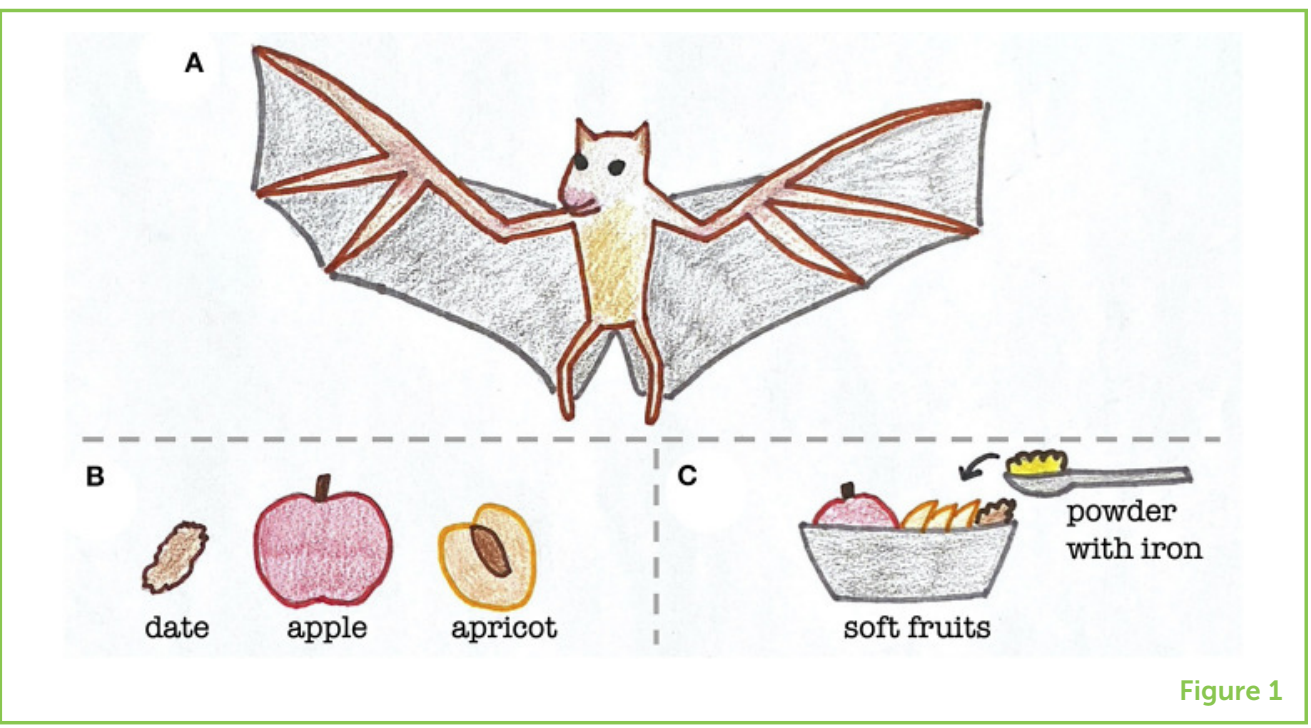

infectious disease, nor did they think these bats died of natural causes, as they were of all different ages and were healthy prior to the onset of illness.

A potential clue stemmed from their diets. At the Toronto Zoo, bats were mostly fed soft fruits, which is what Egyptian fruit bats living in the wild in sub-Saharan Africa, North Africa, and the Middle East also eat [2]. However, zookeepers added a powder to the bats' food that contained various nutrients, similar to vitamin gummies that you could take (Figure 1). The zookeepers gave the bats this powder to keep them healthy, but one of the components, iron, may have unintentionally made them sick. Specifically, there was too much iron in the powder compared to the amount of iron that fruit bats usually eat in the wild.

Curiously, another species of bat at the zoo, the vampire bat, did not get sick despite consuming an iron-rich diet. To better understand why too much iron could make fruit bats so sick while sparing vampire bats, it is first necessary to understand what iron is and why it is important, in moderation, for the well-being of animals.

\section{THE IMPORTANCE OF IRON}

Iron is an element that is essential for most living organisms on Earth. The trees outside your window need iron to survive as much as you, your pet dog, or the bacteria living around you do. Animals generally obtain iron by eating iron-containing foods. You may have already heard that red meat is rich in iron, but there is also iron in eggs, seafood, spinach, tofu, and a variety of other foods. Sometimes a food may not naturally contain iron, but iron will be added to it when it is processed, because it is an essential nutrient to keep people healthy. As a result, even your milk or breakfast cereal could contain iron. 
Figure 2

The path iron takes through the human body. (A) Structure of the stomach, intestines, and liver in humans. Iron is absorbed through the lining of the small intestine with the help of iron transporters. (B) Structure of a human bone, showing bone marrow and a close-up of a red blood cell.

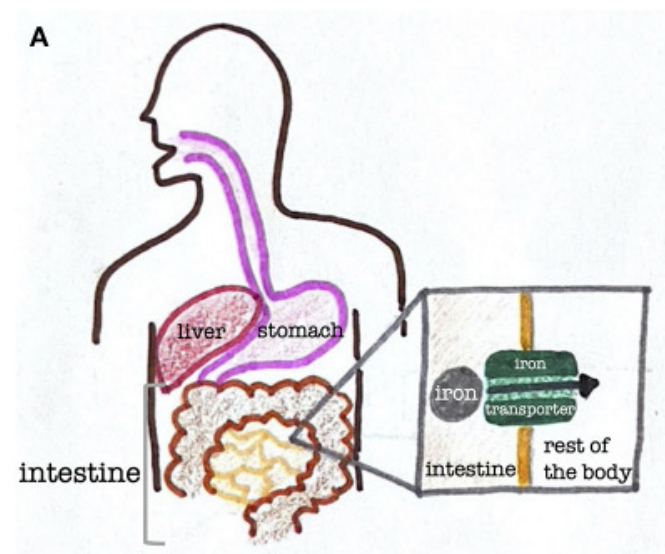

B

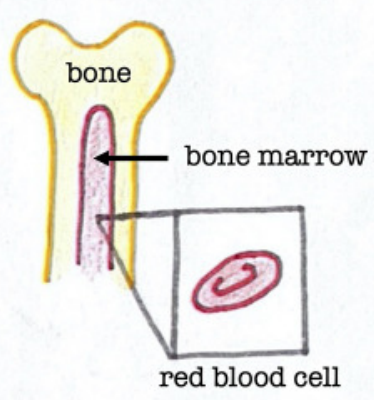

Figure 2

Why is iron so important? It is a key component of many fundamental processes needed for staying alive. For example, we need it to create energy to fuel our bodies, as well as to properly use the oxygen we breathe [3]. There exists a delicate balance, however, because too much iron can also cause us serious damage. As a result, our bodies have found ways to regulate the amount of iron inside of us at any given time.

\section{IRON'S JOURNEY THROUGHOUT THE BODY}

Are you curious about how our bodies actually take up and use iron? To find out, let us track the journey of iron throughout the human body. Although we will use the example of humans, similar processes happen in other animals, such as bats.

When you eat an iron-containing food like red meat, it first enters your stomach and begins to be digested (Figure 2). Next, in the small intestine, which is a part of the digestive system that connects to your stomach, the iron is absorbed. For this absorption to occur, there is a special structure called an iron transporter that allows iron to travel between the body's cells. Iron needs iron transporters to move around because each cell is bordered by a membrane, which is the outermost layer of the cell. Think of the membrane as the walls surrounding your room. Instead of hurling yourself at the wall and hoping to get to the next room, you would use doors to get between the rooms, which is similar to how iron uses iron transporters to move from cell to cell inside the body [4].

Once iron gets absorbed by the digestive system, it travels through the blood to get to other destinations throughout the body. Since iron can be toxic, molecules in the blood called proteins surround it throughout the transport process so it cannot harm us. Most of the iron in our bodies goes to the bone marrow, which is a tissue at the center of our 


\section{HEMOGLOBIN}

A protein that carries oxygen and requires iron to function. It is a component of red blood cells.

\section{IRON DEFICIENCY}

ANEMIA

A condition caused by a lack of iron in the body that results in fatigue and weakness, amongst other symptoms.

\section{IRON OVERLOAD}

A condition caused by an excess of iron in the body that can cause organ damage.

\section{HEPCIDIN}

A protein that regulates iron in our bodies. When there is too much iron, hepcidin causes iron to decrease, and when there is too little, hepcidin causes iron to increase. bones (Figure 2). This is because the bone marrow makes red blood cells, which are cells that carry oxygen throughout the body. Red blood contains hemoglobin, which is a donut-shaped protein that needs iron to help it carry oxygen at its center. In other words, most of the body's iron goes to the bone marrow because the hemoglobin needs it to carry oxygen to the rest of the body.

Some of the iron we eat is stored for later use. Specifically, the iron goes to the liver, which is an organ in the top right part of our abdomens, nestled under the rib cage (Figure 2). The liver has many functions, one of which is the storage of iron.

\section{IRON: IT IS ALL ABOUT BALANCE}

Considering how many important life processes are dependent on iron, you would be right to assume that without enough iron, you would get quite sick. This condition is called iron deficiency anemia, and it can occur for a variety of reasons, including loss of blood and insufficient iron in your diet. Iron deficiency anemia causes you to be weak and makes you tired, and it may even make you want to eat ice or dirt. Fortunately, there is a relatively simple cure for this condition, in the form of iron pills a doctor can prescribe [3].

On the opposite side of the spectrum, iron overload is a condition that occurs when there is too much iron in the body. Patients with iron overload can also experience symptoms, such as weakness and fatigue. The condition can even cause damage to organs, such as the liver, where iron is stored. One treatment for iron overload involves drawing blood from patients until their iron levels decrease. Both iron deficiency anemia and iron overload can be diagnosed by a doctor through blood tests.

Luckily for us, we have a substance called hepcidin that regulates iron levels within our bodies (Figure 3) [3]. When there is too much iron in the body, the amount of hepcidin increases, which causes the level of iron to drop. When there is not enough iron, the amount of hepcidin decreases, which allows the body to absorb more of the iron that is consumed.

\section{THE FINAL PIECE OF THE PUZZLE: HEPCIDIN}

Let us return to the case of the Egyptian fruit bats at the zoo. Knowing the dangers of iron deficiency anemia, you can now understand why the zookeepers wanted to add a nutritious powder containing iron to their food. You also now understand how this powder led to iron overload, which ended up making the bats very sick and hurting their livers. Humans can get iron overload too, if they eat too much iron or if their bodies improperly handle the amount of iron they take in. 
Figure 3

The importance of hepcidin in regulating iron in the body. (A) In response to too much iron in the body, hepcidin levels increase to help lower the iron level. (B) When there is too little iron, hepcidin decreases to allow more iron to enter the body

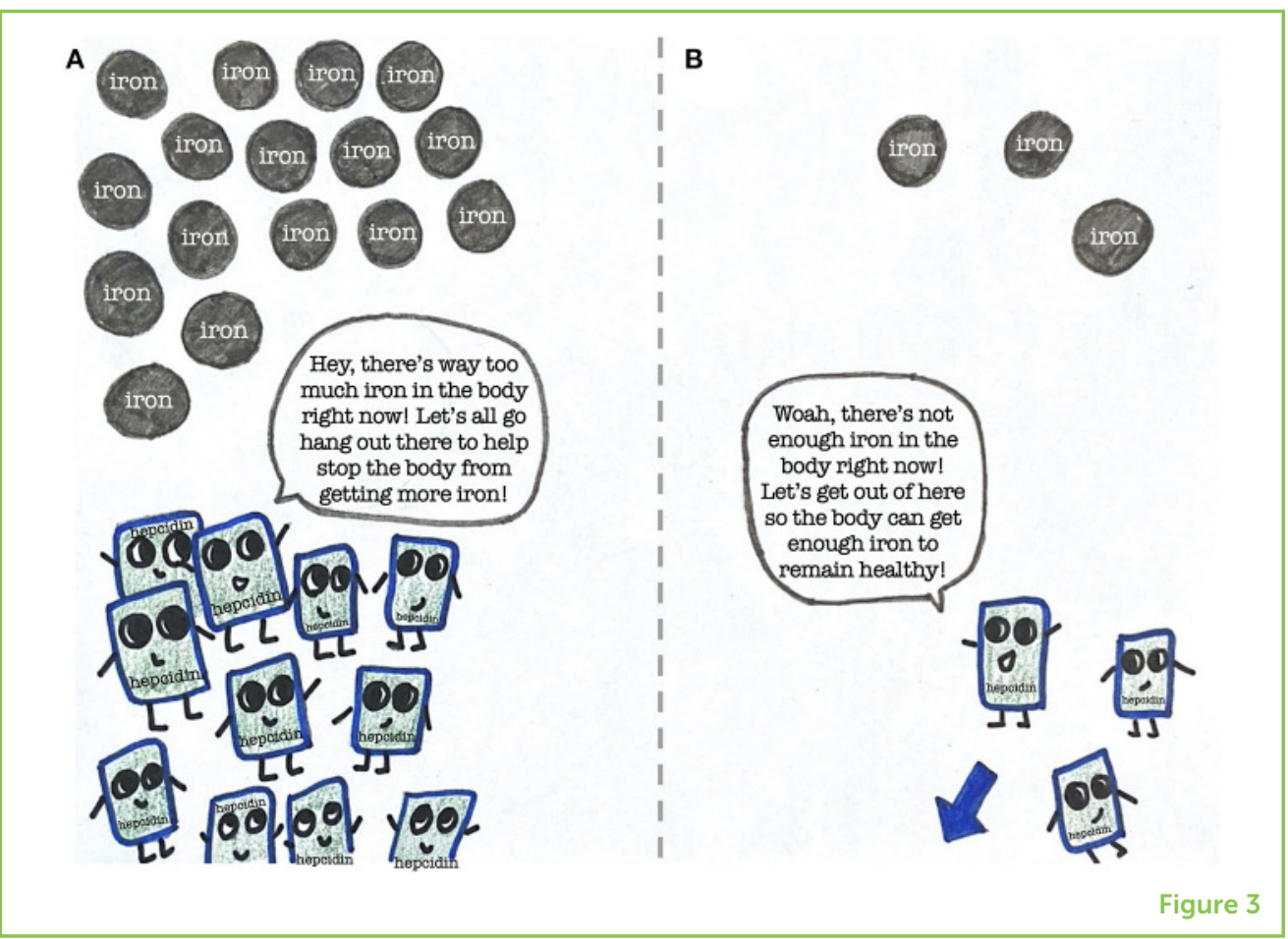

As mentioned earlier, there is one very curious remaining piece of the puzzle. Even though vampire bats at the zoo ate the same iron-rich diet as the Egyptian fruit bats, they did not get sick at all! The reason could be due to hepcidin, the regulator that controls how much iron can be absorbed by the body. Vampire bats drastically adjusted the amount of hepcidin in their bodies to counteract the increased iron in their food, but the Egyptian fruit bats had a difficult time adjusting their hepcidin levels [5]. Since vampire bats are used to consuming blood, which is rich in iron, their bodies may have adapted to tolerate high amounts of iron. Fruit bats, on the other hand, are used to eating diets low in iron. This may be why their hepcidin had difficulty reacting to the excess iron, and as a result, why they got so sick from an iron-rich diet.

\section{SUMMARY}

Iron is essential to our well-being, but it is also harmful in excess. From our food, we obtain iron, which goes through an extensive process to get from our stomachs all the way to our bone marrows, bloodstreams, and livers. Since it is necessary for life's vital processes, too little iron can result in a condition called anemia, but too much can result in iron overload. This is exactly what happened to Egyptian fruit bats at the Toronto Zoo! Thus, living organisms, including you, me, and the Egyptian fruit bats, should eat iron-containing foods in moderation to stay healthy. 


\section{REFERENCES}

1. Crawshaw, G., Oyarzun, S., Valdes, E., and Rose, K. 1995. "Hemochromatosis (iron storage disease) in fruit bats," in Proceedings of the First Conference on Zoo and Wildlife Nutrition (Scarborough, OT: AZA Nutrition Advisory Group).

2. IUCN Red List of Threatened Species. Available online at: https://www.iucnredlist.org/species/29730/22043105 (accessed June 19, 2020).

3. Abbaspour, N., Hurrell, R., and Kelishadi, R. 2014. Review on iron and its importance for human health. J. Res. Med. Sci. 19:164-74.

4. Waldvogel-Abramowski, S., Waeber, G., Gassner, C., Buser, A., Frey, B. M., Favrat, B., et al. 2014. Physiology of iron metabolism. Transfus. Med. Hemother. 41:213-21. doi: 10.1159/000362888

5. Stasiak, I. M., Smith, D. A., Ganz, T., Crawshaw, G. J., Hammermueller, J. D., Bienzle, D., et al. 2018. Iron storage disease (hemochromatosis) and hepcidin response to iron load in two species of pteropodid fruit bats relative to the common vampire bat. J. Comp. Physiol. B Biochem. Syst. Environ. Physiol. 188:683-94. doi: 10.1007/s00360-018-1155-4

SUBMITTED: 22 June 2020; ACCEPTED: 23 March 2021;

PUBLISHED ONLINE: 16 April 2021.

EDITED BY: Daniel F. Hermens, University of the Sunshine Coast, Australia

CITATION: Kim LJ and Jeong J (2021) Bats, Blood, and the Biology of Iron: It Is All About Balance. Front. Young Minds 9:575121. doi: 10.3389/frym.2021.575121

CONFLICT OF INTEREST: The authors declare that the research was conducted in the absence of any commercial or financial relationships that could be construed as a potential conflict of interest.

COPYRIGHT @ $2021 \mathrm{Kim}$ and Jeong. This is an open-access article distributed under the terms of the Creative Commons Attribution License (CC BY). The use, distribution or reproduction in other forums is permitted, provided the original author(s) and the copyright owner(s) are credited and that the original publication in this journal is cited, in accordance with accepted academic practice. No use, distribution or reproduction is permitted which does not comply with these terms.

\section{YOUNG REVIEWER}

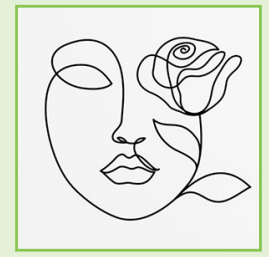

\section{TIANA, AGE: 13}

$\mathrm{Hi}$, my name is Tiana. I enjoy dancing and being creative. I love spending time at the beach. I am interested in learning more about how the human body works.

\section{AUTHORS}

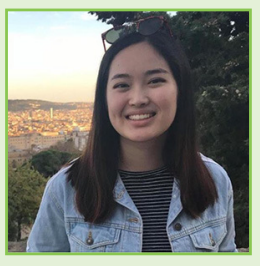

\section{LEAH J. KIM}

I am a recent graduate of Amherst College, where I am currently working as a 
research assistant in the Department of Biology. In the lab, I study how plants transport, store, and use iron. I also enjoy coordinating science outreach events with local schools. In the fall, I will be attending medical school. In my spare time, I enjoy playing with my dog, running, baking, and learning languages.

\section{JEEYON JEONG}

I am a Biology Professor at Amherst College. I teach Molecular Genetics and Biochemistry, and study genes and proteins that help plants acquire and use iron. Besides research and teaching, I love hanging out with my children and enjoy going to concerts-chamber music and musicals are my favorites. *jjeong@amherst.edu 